\title{
A generalised solution for step-drawdown tests including flow dimension and elasticity
}

\author{
GJ van Tonder*, JF Botha and J van Bosch \\ Institute for Groundwater Studies, University of the Free State, Bloemfontein 9300, South Africa
}

\begin{abstract}
Step-drawdown and multi-rate tests present convenient tools for the estimation of the long-term yield of boreholes. However, the analytical methods commonly employed for the analysis of such tests are all based on the assumption that the drawdown in a borehole is a linear function of the discharge rate. Numerous constant rate tests, of which a few are discussed in this paper, has shown that this is not necessarily the case with boreholes drilled in the Karoo formations of South Africa. The drawdowns in these boreholes are not only influenced by the peculiar geometry of the aquifers, but also the non-linear deformation of the aquifers during the pumping of a borehole. The two new non-linear models for the analysis of step-drawdown and multi-rate tests introduced here, tries to account for these factors; in particular the deformation of the aquifer, flow dimension and dewatering of discrete fractures. Although the model proposed for multi-rate tests is still based on constant time steps, the one for step-drawdown tests allows the user to use arbitrary time steps, when performing the test in the field.

Non-linearities in drawdown curves should always be treated with caution, especially when used to assign sustainable yields for boreholes. However, the example of a step-drawdown test performed at the Campus Test Site of the University of the Free State, shows that non-linearities can be addressed with an appropriate model.
\end{abstract}

\section{Introduction}

Step-drawdown tests were introduced by Jacob (1947) to study the influence that the discharge rate, $\mathrm{Q}$, has on the drawdown, $\mathrm{s}(\mathrm{r}, \mathrm{t})$, of the water level in a borehole. His conclusion, based on a number of drawdown tests, was that the observed drawdown consists of two components-one linear in Q and the other one non-linear. He also showed that the linear component can be divided into what he called 'the linear aquifer loss coefficient', which he denoted by the symbol $B_{1}\left(r_{w}, t\right)$, and a 'linear well loss coefficient, $B_{2}$, caused by the loss of energy in the borehole itself. The former of these components can be viewed as the drawdown one would observe if water could be withdrawn from an aquifer without the loss of energy represented by the term $B_{2}$. In other words, $B_{1}\left(r_{w}, t\right)$ can be interpreted as the theoretical solution of the groundwater flow equation for the actual, physical aquifer. It is, consequently, impossible (at least at this moment) to distinguish between the two linear losses in practice. Jacob, therefore, combined the two terms into the linear loss coefficient, defined by the equation:

$$
B\left(r_{e}, t\right)=B_{1}\left(r_{w}, t\right)+B_{2}
$$

where $r_{e}$ is known as the effective radius of a borehole, with physical radius $r_{w}$. Jacob defined $r_{e}$ as the radial distance from the vertical axis of the borehole to a point where the water level in the aquifer equals the water level in the borehole. This interpretation led him to describe the observed drawdown in a pumped borehole, $\mathrm{s}_{\mathrm{w}}$, with the equation:

$$
s_{w}=B\left(r_{e}, t\right) Q+C Q^{2}
$$

* To whom all correspondence should be addressed.

III (051) 401-2840; fax: (051) 447-3541; e-mail: Gerrit@IGS-NT.uovs.ac.za

Received 22 July 1999; accepted in revised form 23 February 2001. where the term $\mathrm{CQ}^{2}$, represents the non-linear losses.

The main effect of the non-linear losses is to drive the water level in the borehole down, without contributing to Q. This could not only affect the operational costs of a borehole adversely, but could also cause irreparable damage to the borehole, pump and even the aquifer. It is very important that one should never operate a borehole in such a way that the non-linear energy losses become dominant. However, it may sometimes be necessary to sacrifice energy for the borehole to perform optimally. Since this was the main motivation for Jacob to introduce step-drawdown tests, it is not surprising to find that Eq. (1) can be very useful in this regard.

It is common practice to assume that the coefficient $C$ in Eq. (1) is constant and attribute the existence of the term $\mathrm{CQ}^{2}$ to turbulent flow, caused by the pump in and near the borehole (Helweg, 1994). However, there are indications that the drawdown is not only a function of Q, but also the geometry of the aquifer and that this may contribute to the non-linear term in Eq. (1) and cause the parameters $\mathrm{B}_{2}$ and $\mathrm{C}$ to be time-dependent. Helweg suggests that Eq. (1) be replaced by the equation:

$$
s=\left[A+B^{\prime} \log (t)\right] Q+\left[C^{\prime} \log (t)\right] Q^{p}
$$

which he claims is more general than Eq. (1). This is certainly true in the sense that Eq. (2) allows the coefficients to be time-dependent. However, to achieve this he assumed that the theoretical drawdown, $\mathrm{B}_{1}\left(\mathrm{r}_{\mathrm{w}}, \mathrm{t}\right)$, could be represented by the Cooper-Jacob approximation of the Theis solution for an infinite uniform aquifer. Since this assumption is not necessary in Eq. (1), the possibility exists that Eq. (1) may describe the drawdowns of boreholes in heterogeneous aquifers better than Eq. (2), if the time is kept constant.

Another consequence of Helweg's assumption is that the flow towards the borehole must be radial, which need not be the case. This seems to be particularly the case with the shallow aquifers in the geological formations associated with the Karoo Supergroup in South Africa. These formations, which underlie approximately $50 \%$ of the country, consist mainly of sandstones, mudstones, 


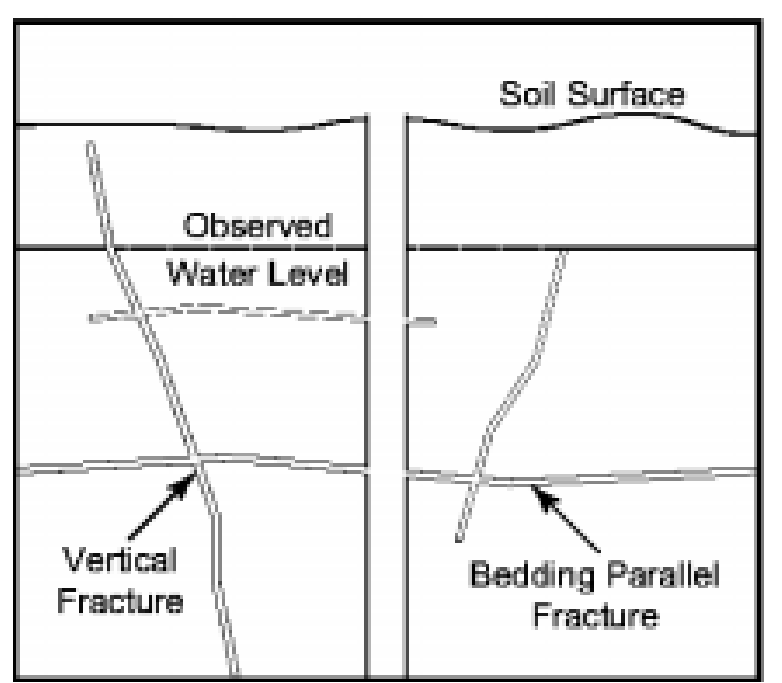

Figure 1

Schematic cross-section through a typical Karoo aquifer

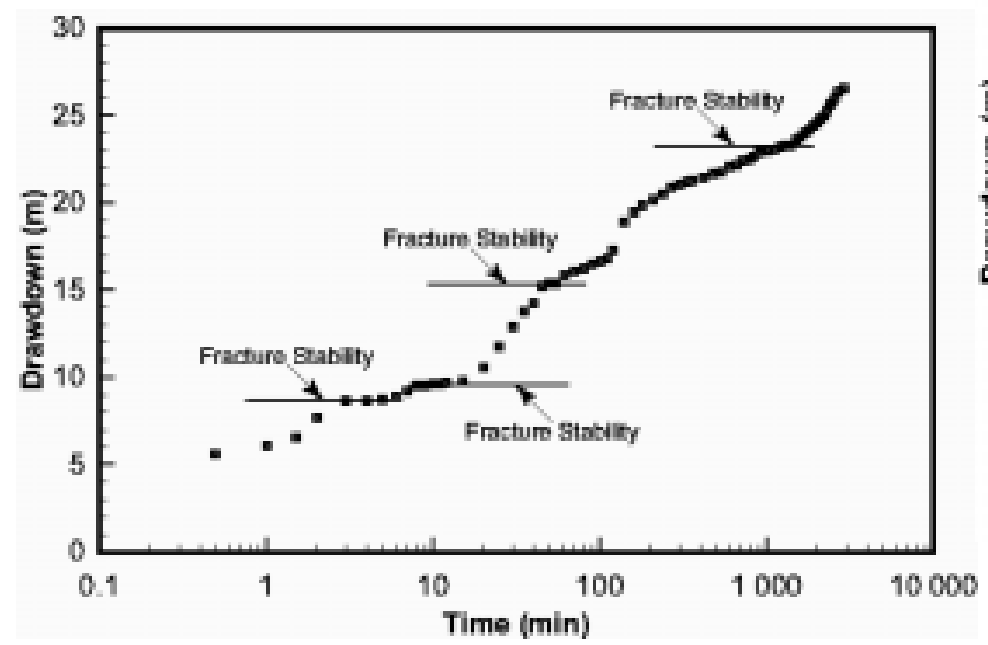

Figure 2

The drawdown observed during a constant rate test on a borehole in the Karoo Supergroup pumped at a constant rate of $15 \mathrm{l} \cdot \mathrm{s}^{-1}$
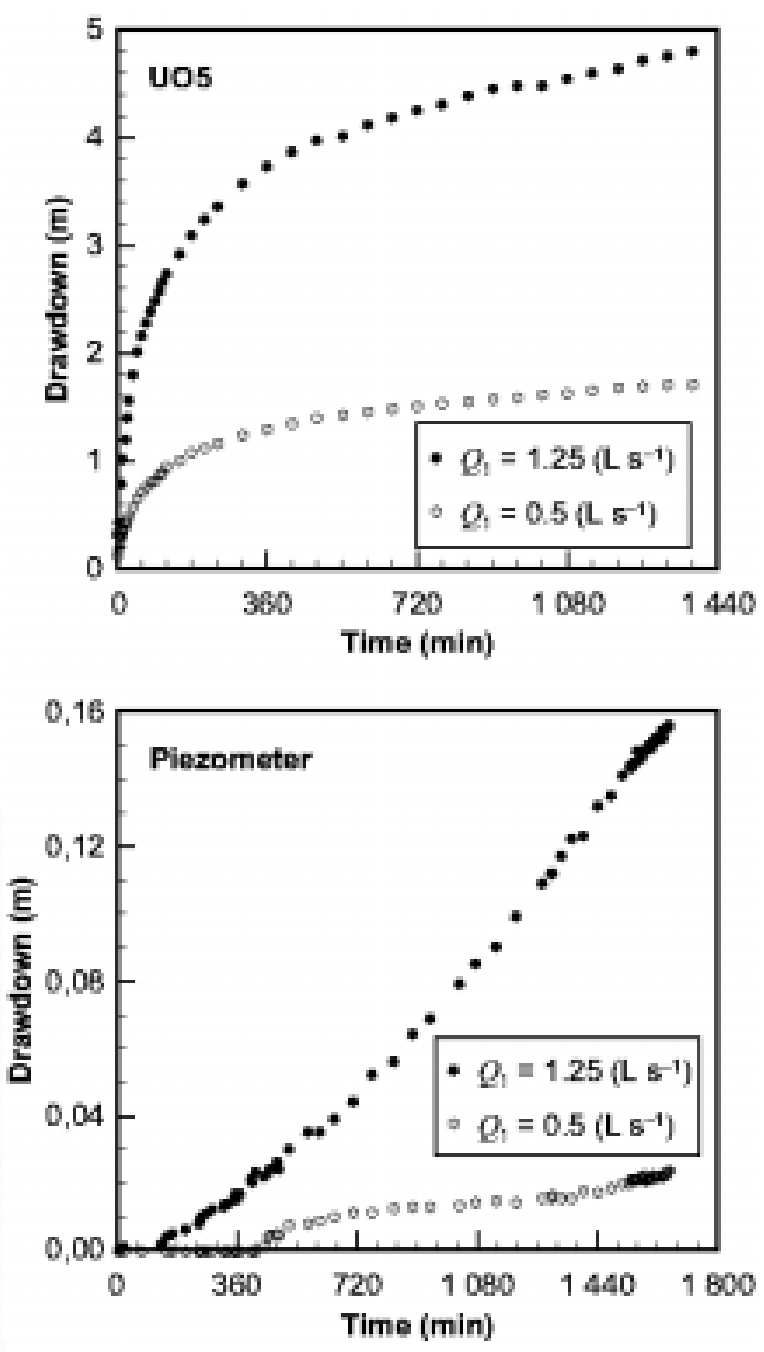

Figure 3

Drawdowns observed in UO5 and the piezometer installed in UO6, $5 \mathrm{~m}$ from UO5, when UO5 was pumped at the given rates shales and siltstones. The isostatic uplift of Karoo sediments and the intrusion of Drakensberg lavas and dolerites have fractured these formations, particularly the sandstone layers that are less elastic than the rest of the rocks in the Supergroup. Karoo aquifers therefore, normally contain one (sometimes a few) bedding parallel fracture, as illustrated in Fig. 1, that serves as the main conduit of water for boreholes in the aquifers (Botha et al., 1998). The drawdown observed during a constant rate test on such a borehole consequently displays a completely different behaviour than the drawdown in a conventional borehole. If borehole storage is neglected, the drawdown initially follows a linear trend, as shown in Fig. 2, which suggests that the borehole receives its water from the bedding plane fracture. This period is followed by one in which the flow is bi-linear, when the borehole receives water from both the fracture and the rock matrix. Although the water level at first continues to decrease during this period, it ultimately tends to stabilise on or just above the bedding parallel fracture, provided that the discharge rate of the borehole does not exceed the rate at which the matrix can recharge the fracture. Otherwise, the water level will begin to decline again and stabilises above another fracture (if one is present), or simply drops to the pump intake. The drawdowns observed in Karoo boreholes depend not only on the discharge rates of the boreholes, as implied in the derivations of Eqs. (1) and (2), but also on the geometry of the aquifer.

The dependence of the observed drawdowns in Karoo boreholes on the geometry of the aquifer is not restricted to the dewatering of fractures alone, as illustrated by the results of two constant rate tests performed on borehole UO5 on the Campus Site with discharge rates of $0.5 \ell \cdot \mathrm{s}^{-1}$ and $1.25 \ell \cdot \mathrm{s}^{-1}$. In these tests, water levels were monitored simultaneously in UO5 and a piezometer installed in borehole UO6, situated $5 \mathrm{~m}$ from UO5. The piezometer was installed $2 \mathrm{~m}$ above the bedding parallel fracture that intersects both UO5 and UO6 at a depth of 23 m below surface within a sandstone layer that contains the fracture. The results are summarised in Table 1 and Fig. 3.

As shown in Fig. 3, the water level in UO5 never dropped below the fracture in both tests, while the ratio of its water levels (after one day of pumping) in Table 1 is also very similar to the ratio of the discharge rates. However, the drawdowns observed in the piezometer differ by a ratio of 6.5 . This behaviour can be explained briefly as follows. 

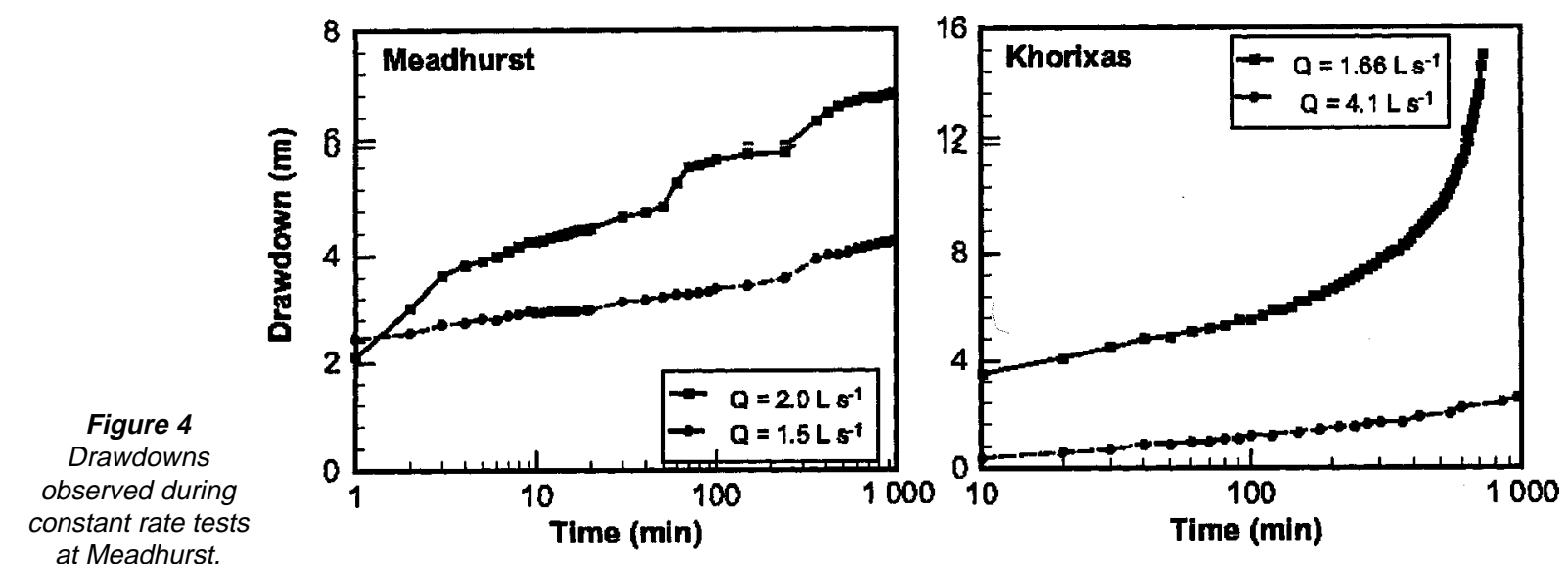

at Meadhurst

Khorixas and the

boreholes

Zonnebloem 1 and

2 of the Middelburg Municipality
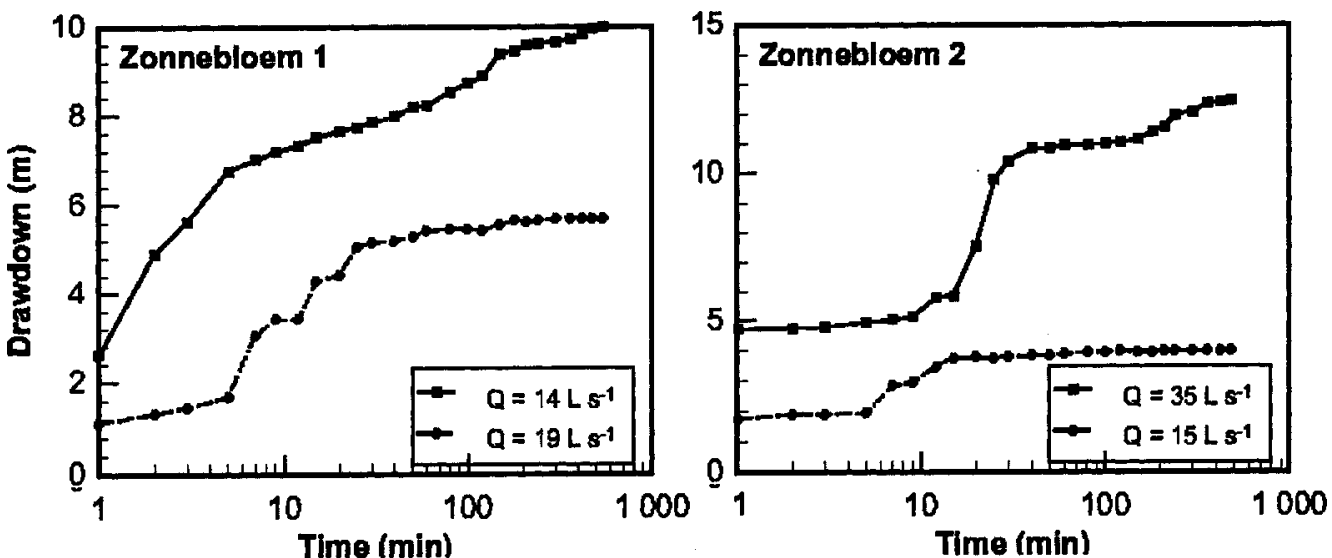

TABLE 1

Water levels observed in Borehole UO5 on the campus test site and a piezometer installed in

Borehole UO6, $5 \mathrm{~m}$ from UO5, during two pumping tests with different abstraction rates

\begin{tabular}{|l|c|cc|}
\hline \multirow{2}{*}{} & \multirow{2}{*}{$\begin{array}{c}\mathbf{Q} \\
(\ell / \mathbf{s})\end{array}$} & \multicolumn{2}{|c|}{ Drawdown after one day (m) } \\
\cline { 3 - 4 } & & UO5 & $\begin{array}{c}\text { Piezometer } \\
\text { in UO6 }\end{array}$ \\
\hline & & & 0.024 \\
& 0.50 & 1.72 & 0.156 \\
Ratio & 1.25 & 4.82 & 6.500 \\
\hline
\end{tabular}

It is known that the rocks serve as the main reservoir for water in Karoo aquifers. However, the vertical and horizontal hydraulic conductivities of the Karoo rocks are very low $\left(\sim 10^{-7} \mathrm{~m} \cdot \mathrm{s}^{-1}\right.$ to $\left.10^{-8} \mathrm{~m} \cdot \mathrm{s}^{-1}\right)$. The bedding parallel fractures, on the other hand, have very high horizontal hydraulic conductivities $\left(\sim 10^{-4} \mathrm{~m} \cdot \mathrm{s}^{-1}\right)$ and, consequently, can transmit large quantities of water quickly. Very little water flows through undisturbed Karoo aquifers under natural conditions. It is only when the piezometric pressure in a bedding parallel fracture is disturbed that the vertical piezometric gradient and gravity force the water to flow from the rock matrix to the fracture. The main direction of flow in these aquifers is vertical and linear, and not horizontal and radial as in conventional aquifers (Botha et al., 1998).

Because the flow is vertical, a Karoo borehole will first dewater the rock matrix in its immediate vicinity, before it begins to dewater the matrix at more distant points. One would, of course, expect the opposite situation to arise after the pump has been switched off, that is the water levels in the pumped borehole and surrounding rock matrix will restore more rapidly than water levels at more distant points in the aquifer. It is very interesting to note that although the water levels in UO5 were restored very quickly, the piezometer level in UO6 continued to decline for $5 \mathrm{~d}$, after the pump was switched off in the $0.5 \ell \cdot \mathrm{s}^{-1}$ test, and $14 \mathrm{~d}$ after the $1.25 \ell \cdot \mathrm{s}^{-1}$ test. The water levels near the borehole were not only restored first, but also at the expense of the piezometric levels within the rock matrix. However, there are indications that this delay in the restoration of the water levels in the matrix is enhanced by the restoration of the fracture geometry, which was deformed during the pumping operations.

The previously described heterogeneous behaviour of the water levels has been observed in many constant rate tests performed in Southern Africa. The results of four of these tests are summarised in Table 2 and illustrated graphically in Fig. 4. The first test was performed on a borehole in the mudstone aquifer at Meadhurst (just west of Bloemfontein) and the second on a borehole in the calcrete aquifer of Khorixas in Namibia. The other two were performed on the boreholes Zonnebloem 1 and 2 of the Middelburg Municipality in the Northern Cape Province.

There is a possibility that the sharp increase in the drawdown of the Khorixas borehole at the late times in Fig. 4 was caused by boundary effects. The reason for this belief is that the increase in the drawdown is smooth and not stepwise as in the other boreholes

The previous examples clearly suggest that Eqs. (1) and (2) cannot fully account for the heterogeneities in Karoo aquifers, caused by their particular geometry. A new method was developed for the analysis of these boreholes. However, the idea behind the method may be better understood if one has a good understanding of how these tests are performed and the factors that may influence 
TABLE 2

Ratios of the abstraction rates, $Q$, and associated drawdowns, $s\left(t_{d}\right)$ observed during pumping tests with durations $t_{d}$ on four boreholes in Southern Africa

\begin{tabular}{|c|c|c|c|c|c|}
\hline \multirow[t]{2}{*}{ Meadhurst } & \multicolumn{2}{|c|}{$t_{d} 950 \mathrm{~min}$} & \multirow[t]{2}{*}{ Khorixas } & \multicolumn{2}{|c|}{$t_{d} 420 \min$} \\
\hline & $\mathbf{Q}\left(\ell \cdot \mathbf{s}^{-1}\right)$ & $s\left(t_{d}\right)(m)$ & & $\mathbf{Q}\left(l \cdot \mathbf{s}^{-1}\right)$ & $s\left(t_{d}\right)(m)$ \\
\hline & 1.5 & 4.24 & & 1.66 & 1.9 \\
\hline & 2.0 & 6.83 & & 4.1 & 8.8 \\
\hline Ratio & 1.33 & 0.62 & Ratio & 2.47 & 4.6 \\
\hline \multirow[t]{2}{*}{ Zonnebloem 1} & \multicolumn{2}{|c|}{$t_{d} 540 \mathrm{~min}$} & Zonnebloem 2 & \multicolumn{2}{|c|}{$t_{d} 540 \min$} \\
\hline & $\mathbf{Q}\left(\ell \cdot \mathbf{s}^{-1}\right)$ & $s\left(t_{d}\right)(m)$ & & $\mathbf{Q}\left(\ell \cdot \mathbf{s}^{-1}\right)$ & $s\left(t_{d}\right)(m)$ \\
\hline & 14 & 5.68 & & 15 & 4.01 \\
\hline & 19 & 9.98 & & 35 & 12.43 \\
\hline Ratio & 1.36 & 1.75 & Ratio & 2.33 & 3.01 \\
\hline
\end{tabular}

the dependence of $s_{w}$ on the discharge rate. The discussion that follows begins with a brief discussion of the basic principles that underlies the application of Eqs. (1) and (2) and the methods conventionally used to analyse the yields of borehole. This is followed by a discussion of the various factors that may influence the behaviour of boreholes, the new approach developed for Karoo aquifers and the application of the method to a typical borehole in a Karoo aquifer.

\section{Principles and methods used in the analysis of borehole yields}

\section{General}

It is well-known that Eq. (1) can only be applied in practice once a suitable time has been chosen for a drawdown test (Helweg, 1994). The reason for this is that the coefficient $B_{1}\left(r_{w}, t\right)$ in Eq. (1) is time-dependent. Its contribution to $\mathrm{s}_{\mathrm{w}}$ can only be neglected if the tests are performed for the same period. However, there is another implicit assumption in the equation that is often overlooked-the assumption that the theoretical drawdown can be expressed in the form

$$
s\left(r_{w}, t\right)=Q B_{1}\left(r_{w}, t\right)
$$

That this is indeed an assumption follows directly from the observation that the discharge rate appears nowhere in the equation which is universally accepted as the one that describes the flow of groundwater (Bear, 1972; Botha, 1996)

$$
S_{0} D_{t} \varphi(\mathbf{x}, t)=\nabla \cdot[\mathbf{K} \nabla \varphi(\mathbf{x}, t)]+f(\mathbf{x}, t)
$$

This equation only contains the specific storativity, $\mathrm{S}_{0}$, hydraulic conductivity, $\mathrm{K}$, piezometric head, $\varphi$, and the strength of the sink (or source), $\mathrm{f}(\mathrm{x}, \mathrm{t}$ ), apart from the usual spatial and time variables and their derivatives. Since it is impossible to determine the strength of the sink (borehole) with the methods available today, a borehole is commonly regarded as a line sink, and $\mathrm{f}(\mathrm{x}, \mathrm{t})$ expressed as

$$
f(x, t)=Q \delta\left(x-x_{0}\right) \delta\left(y-y_{0}\right)
$$

where:

$\delta\left(z-z_{0}\right)$ is the well-known Dirac delta function,

$\left(\mathrm{x}_{0}, \mathrm{y}_{0}\right)$ the horizontal position of the borehole.

However, this immediately removes any dependence of $s_{r}\left(r_{w}, t\right)$ on the heterogeneity of the aquifer and forces it to be a linear function of $\mathrm{Q}$, which need not be the case in general, as illustrated by the previous discussion of the drawdowns observed in Karoo boreholes. Unfortunately, Eq. (4) probably represents the best assumption until it becomes possible to quantify $f(x, t)$ directly. One must always apply Eqs. (1) and (2) with care.

\section{Field methods used to estimate borehole losses}

There are two field methods for the estimation of well losses - the well-known step-drawdown test and the multi-rate test. The main difference between the two tests is that the water level is allowed to recover between the steps of a multi-rate test, while the stepdrawdown test is a continuous test, as illustrated by the schematic drawdowns in Fig. 5.

It is, in principle possible to disrupt the restoration of the water level in multi-rate tests. However, it must be kept in mind that the solution of Eq. (3) for variable discharge rates has a memory, which needs to be taken into account in the analysis of the results, as shown by the various methods, such as the Hantush-Bierschenk method, often used to analyse step-drawdown tests (Kruseman and De Ridder, 1991). A similar procedure will not only complicate the analysis of a multi-rate test, but also affect the reliability of the results adversely.

Multi-rate tests are not much favoured in groundwater hydraulics, because of the extensive periods required for the tests. However, they can be used to determine the coefficients in Eqs. (1) and (2) directly. For example, consider the case where two constant rate tests have been performed on the same borehole, one with a discharge rate $\mathrm{Q}_{1}$ and the other with a discharge rate $\mathrm{Q}_{2}$. Let $\mathrm{s}_{1}$ and $\mathrm{s}_{2}$ represent the observed drawdowns after a fixed time, $\mathrm{t}_{\mathrm{f}}$, and $\mathrm{r}_{1}$ and $\mathrm{r}_{2}$ the ratios $\left(\mathrm{s}_{1} / \mathrm{Q}_{1}\right)$ and $\left(\mathrm{s}_{2} / \mathrm{Q}_{2}\right)$ respectively. It is then not difficult to show that the coefficients $B\left(r_{e}, t\right)$ and $C$ in Eq. (1) must satisfy the relations

$$
B\left(r_{e}, t_{f}\right)=\frac{Q_{2} r_{1}-Q_{1} r_{2}}{Q_{1}-Q_{2}} \quad C\left(t_{f}\right)=\frac{Q_{1}\left(r_{1}-r_{2}\right)}{Q_{1}-Q_{2}}
$$

If applied at different periods, $\mathrm{t}_{\mathrm{f}}$, these expressions can also be used to determine the dependence of $\mathrm{B}\left(\mathrm{r}_{\mathrm{e}}, \mathrm{t}\right)$ and $\mathrm{C}\left(\mathrm{t}_{\mathrm{f}}\right)$ on $\mathrm{t}$, without any assumption on the nature of $B\left(r_{e}, t\right)$.

\section{Non-linearities in the drawdown-discharge curve}

\section{General}

As mentioned in the introduction, the non-linear term, $\mathrm{CQ}^{2}$ in Eq. (1) and $C^{\prime} \log (t) Q^{p}$ in Eq. (2), is conventionally ascribed to turbulence caused by the pumping of the water. However, there are three other phenomena that may also contribute to the non-linear behaviour

- dewatering of discrete fractures,

- deformation of the fractures and/or the rock matrix, and

- a phreatic or water table aquifer. 

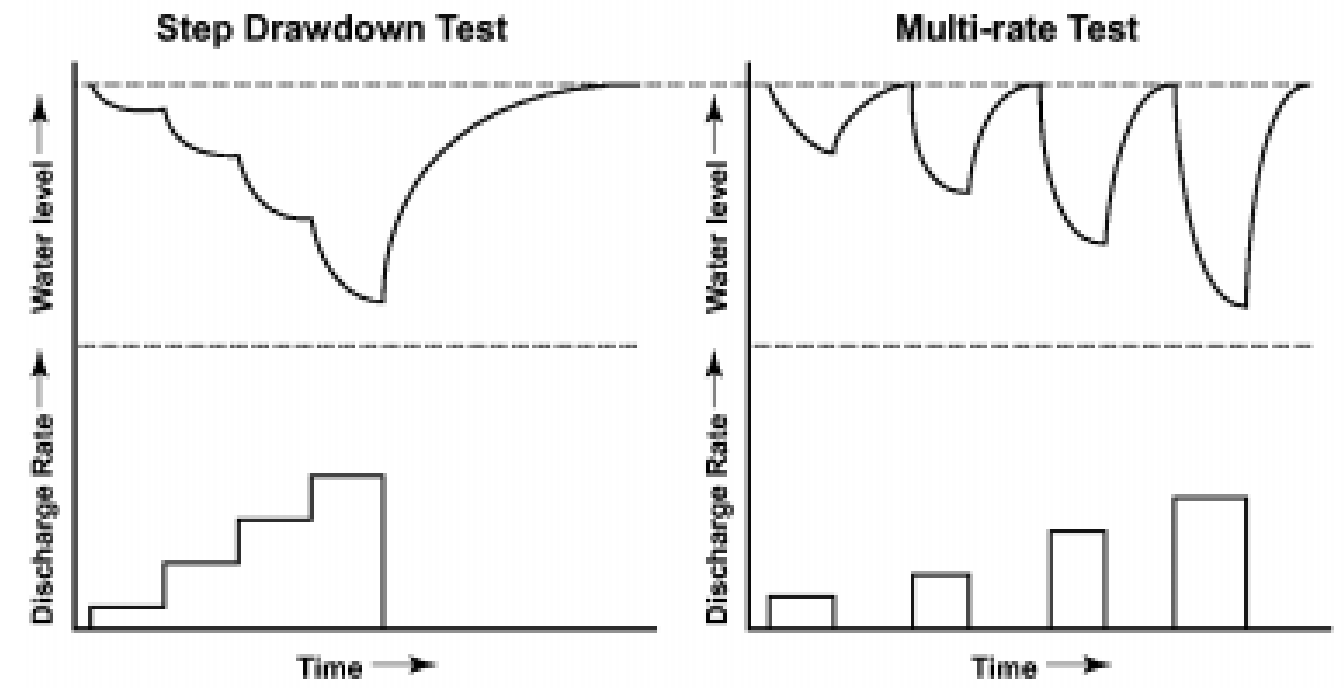

Figure 5

Schematic illustration of the difference in drawdowns observed during a step-drawdown and a multi-rate test

\section{Turbulence}

Turbulence is a characteristic property of any fluid flowing across an obstacle, caused by the interaction between the molecules of the fluid and obstacle, and depends essentially on the roughness and size of the obstacle and the flow velocity. Since turbulence is a very common phenomenon in pipe flow, geohydrologists mainly associate it with fractures and sinkholes. However, two other factors may also contribute to turbulence in a producing borehole - a high discharge rate and a restrictive entry to the borehole. The first of these factors can be controlled by using a judiciously chosen discharge rate (the main reason why Jacob introduced stepdrawdown tests), but the second factor presents some difficulties.

There are a number of reasons why a restrictive entry may develop in a borehole, such as the clogging of the natural pores by drilling mud, fine-grained particles deposited by percussion drills, and the installation of gravel packs. This usually results in the formation of a zone, commonly referred to as a skin, in the immediate domain of the borehole whose hydraulic conductivity, $\mathrm{K}_{\mathrm{s}}$, differs markedly from the hydraulic conductivity, $\mathrm{K}$, of the aquifer outside the skin. Such a skin can be conveniently characterised by the so-called skin factor

$$
\xi=\left\{\frac{K}{K_{s}}-1\right\} \log \left(\frac{r_{s}}{r_{w}}\right)
$$

where $r_{w}$ is the radius of the borehole and $r_{s}$ that of the skin, assuming that the skin does not store water. If it is further assumed that the water levels near the borehole could be described by the Cooper-Jacob approximation, the skin factor can be used to describe Jacob's effective radius, $r_{\mathrm{e}}$ in Eq. (1) with the equation (Matthews and Russell, 1967):

$$
r_{e}=r_{w} \exp (-\xi)
$$

The skin factor can be positive or negative, as illustrated in Fig. 6 . A positive skin factor indicates that the drawdown in the borehole is more than the drawdown expected theoretically for the aquifer and a negative skin factor indicates that the drawdown is less than the theoretical drawdown. A positive skin factor often arises when the skin has been clogged during the drilling operations, while a negative skin factor indicates that the skin is well-developed. The

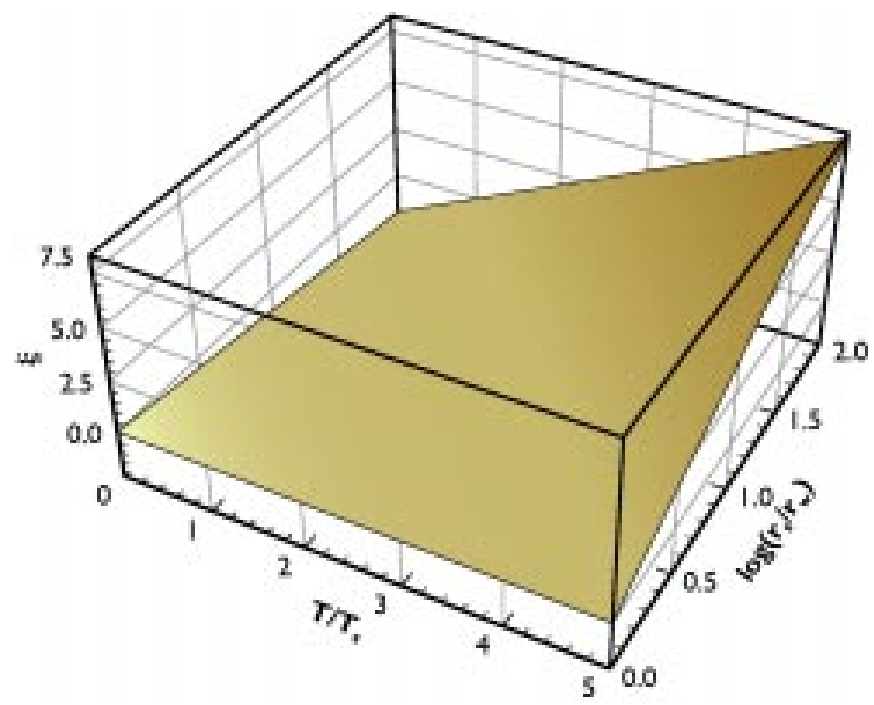

Figure 6

Graph of the skin factor, $\zeta$, as a function of the ratios $\left(T / T_{s}=K / K_{s}\right)$ and $\log \left(r_{s} / r_{w}\right)$ in Eq. (5)

latter situation often arises where a gravel pack has been installed around a producing borehole, but has also been observed in constant rate tests performed on boreholes that intersect horizontal fractures in Karoo aquifers.

As shown in Figs. 2 and 4, the observed drawdown rate in a borehole intersected by a horizontal fracture remains practically constant if the borehole is pumped at a rate that can be sustained by the fracture, but increases sharply if this rate is exceeded. Although the increase in the drawdown rate may be viewed as a non-linearity, it must be remembered that the dewatering of a fracture is largely controlled by the hydraulic conductivity of the rock matrix surrounding the fracture (Botha et al., 1998). This behaviour is similar, but not physically equivalent, to that observed in an aquifer with one or more impermeable boundaries, where the drawdown rate also increases sharply once the pumping begins to influence the water levels on its boundaries. (See for example the drawdown curve for the Khorixas borehole in Fig. 4). One approach to compute discharge rates from these drawdowns would be to use the 


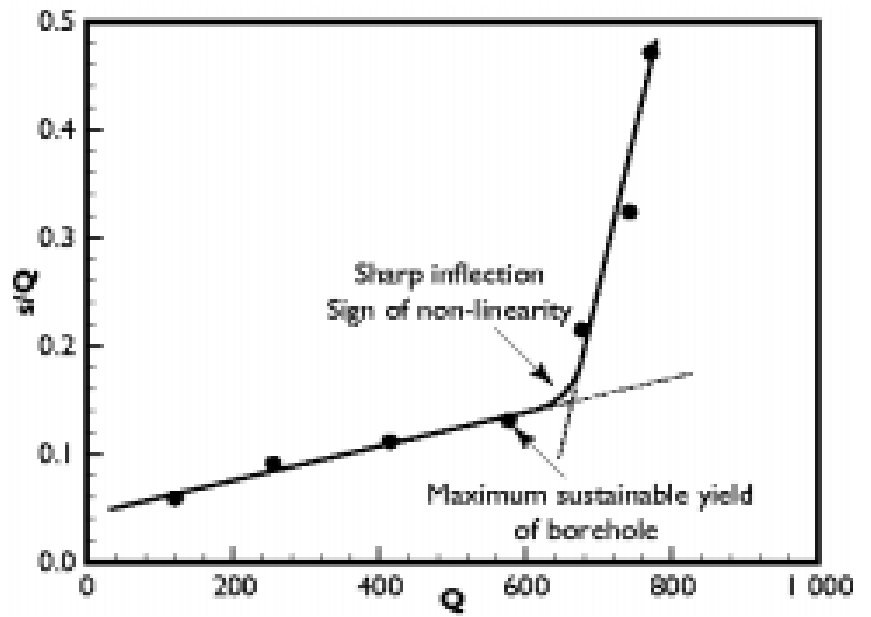

Figure 7

A graph of normalised drawdown, $s / Q$, as a function of the discharge rate, $Q$, used in the analysis of drawdowns in an aquifer with one or more impermeable boundaries

simple graphical technique, illustrated in Fig. 7, often employed in the analysis of aquifers with impermeable boundaries. However, as a comparison of the drawdowns of the Khorixas and Zonnebloem 2 boreholes in Fig. 4 shows, the drawdown rate for the fractured Zonnebloem 2 borehole is larger than that of the Khorixas borehole. The previous procedure may not be suitable in the case where a large increase in the drawdown rate is caused by the dewatering of a fracture.

Previous experience with constant rate tests on boreholes in Karoo aquifers have shown that the non-linear behaviour will always be observed, if the discharge rate of the producing borehole is high enough. Unfortunately, it is very difficult to predict when and at what discharge rate the non-linear behaviour will begin, since that is determined by the areal dimension of the fracture (Gringarten and Ramey, 1974). It may take a long time and a large number of discharge rates to determine the position of the nonlinear behaviour in a borehole that intersects an extensive fracture.

It is tempting to assume that the presence of a prolonged period during which the drawdown remains constant, signifies that the discharge rate used in the test represents an acceptable measure for the long-term yield of the borehole. Unfortunately, this is not necessarily the case. For, as shown by the drawdown curves of borehole Zonnebloem 2 in Fig. 4, both the length of the period and the depth at which the water level stabilises depend on the discharge rate. The possibility exists that one may easily overestimate or underestimate the yield of the borehole, by concentrating on the presence of such a period. This was the main reason for introducing the generalised solution for step-drawdown tests described below.

\section{Deformation}

It may not always be appreciated, but the only reason why groundwater can be withdrawn from the subsurface of the earth is that all the geological formations on earth (and water) are compressible. The result is that an aquifer will always deform to some extent when water is pumped from a borehole drilled into the aquifer. If the stress-strain relation for the formations that governs the deformation is linear, so that is obeys Hooke's law, the formations will restore to their original form once the pumping is stopped, otherwise it will continue to deform with time. Although Eq. (3) accounts for linear deformation in the vertical direction, through the appearance of the compressibility coefficients of the rock and water in the specific storativity (Bear, 1972), it completely neglects horizontal and non-linear deformations. This aspect is currently investigated by Cloot and Botha (2000) with a numerical model for an aquifer consisting of a central sandstone layer bounded on the top and bottom by mudstone layers. Their results can be briefly summarised as follows.

When pumping starts, perturbations in the fluid pressure that develop near the wall of the borehole propagates rapidly through the aquifer, causing deformations in both the horizontal and vertical directions, but on different scales. The horizontal displacements develop uniformly throughout the thickness of the aquifer, but the vertical displacements concentrate on the sandstone-mudstone interfaces. The maximum amplitude of the horizontal deformation, which remains more or less constant, propagates slowly from the borehole wall into the aquifer. The vertical displacement, on the other hand, remains at the interfaces where both its maximum amplitude and extent slowly increases with time. As could have been expected, the deformation does not affect the piezometric head in the different layers adversely at the beginning, but its effect becomes more noticeable with time. However, the linear stressstrain relation ensures that all deformations disappear once the pumping is stopped.

The same situation also develops in the case where the stressstrain relation is non-linear, as long as the deformation is restricted to the linear leg of the relation. However, the deformation amplitudes, particularly that of the vertical displacements, quickly begin to exceed those of the linear stress-strain relation, once the strains exceed the elastic limit. Moreover, the aquifer is not restored to its original dimensions after the pumping has stopped. Since the magnitudes of the pressure perturbations (thus the deformations) are essentially functions of the discharge rate, there is a possibility that a too high discharge rate that is too high may not only damage the aquifer permanently, but ultimately may also causes it to collapse. This applies in particular to any fracture (vertical or horizontal) in the aquifer.

It is important to note that the relation between the computed piezometric head and the discharge rate is always non-linear, even in the case of the linear stress-strain relation. Deformation of the aquifer could, therefore, contribute significantly to the non-linear terms in Eqs. (1) and (2), as mentioned by Helweg (1994). A common rule of thumb to regard a borehole with a coefficient $\mathrm{C}\left[\mathrm{d}^{2} / \mathrm{m}^{6}\right]>10^{-7}$ as one that could be developed to make it more efficient may not be valid for these boreholes.

\section{Phreatic aquifers}

The major characteristic of a phreatic or water table aquifer, and the one that distinguishes it from all other types of aquifers, is that the water table will move in or out of the unsaturated zone that overlies the water level in such an aquifer. This type of aquifer has to be described by the unsaturated-saturated flow equation

$$
\left[S_{w} S_{0}+C(\varphi)\right] D_{t} \varphi(\mathbf{x}, t)=\nabla \cdot[\{\mathbf{K}(\varphi) \nabla \varphi(x, t)\}]+f(\mathbf{x}, t)
$$

where $S_{w}$ is the water saturation and $C(\varphi)$ the moisture capacity, while the other symbols have the same meaning as in Eq. (3). This is a highly non-linear equation in the mathematical sense in that it does not obey the principle of superposition (Cakmak and Botha, 1995), since both $C(\varphi)$ and $K(\varphi)$ are functions of the piezometric head. However, this does not imply that the drawdown in such an aquifer will be a non-linear function of $\mathrm{Q}$, as is often believed. Indeed, it is not difficult to see that the latter relation will still be 
linear if the source strength, $\mathrm{f}(\mathrm{x}, \mathrm{t})$, is approximated with Eq. (4). One reason for the belief that the drawdown in these aquifers is a non-linear function of the discharge rate, is probably because such aquifers are often viewed as a confined aquifer in which the transmissivity, $\mathrm{T}$, varies with the saturated thickness of the aquifer. However, as shown by the Dupuit formula for phreatic aquifers (Kruseman and De Ridder, 1991), this would imply that the drawdown should behave as a function of $\mathrm{Q}^{1 / 2}$ and not $\mathrm{Q}^{\mathrm{p}}$, with $\mathrm{p}>1$, as is conventionally assumed for the non-linear term in both Eqs. (1) and (2).

\section{The fractal behaviour of drawdown}

A common implicit assumption in the analysis of drawdown tests is that all points in an aquifer are equally accessible to the borehole. In other words, the rate at which water will flow from a point $A$ in the aquifer to the borehole will depend only on the discharge rate of the pump and not on the geometry of the aquifer in the vicinity of A. However, this may not be the case in Fig. 8 where UO5 will more likely withdraw water from point $A$ than point $B$, even though $\mathrm{B}$ is situated closer to UO5. This behaviour prompted Barker (1988) to introduce what he calls the flow dimension for flow through a fracture - a concept based on his fractalisation of the spherical surface element (but not the spherical space itself). This allows him to express the drawdown in a uniform infinite aquifer in his hybrid space as:

$$
\varphi(r, t)=\frac{Q r^{2 v}}{4 \pi^{1-v} K_{f} b^{3-n}} \Gamma(-v, u) ; \quad v<1 ; \ldots . . u=\frac{r^{2} S_{f}}{4 K_{f} t}
$$

where:

$$
\begin{aligned}
\mathrm{r} & =\text { the radius vector in spherical space } \\
\mathrm{n} & =\text { the flow dimension } \\
\mathrm{S}_{\mathrm{f}}, \mathrm{K}_{\mathrm{f}}= & \text { the specific storativity and hydraulic } \\
& \text { conductivity of the fracture } \\
\mathrm{v} & =1-\mathrm{n} / 2 \\
\mathrm{~b} & =
\end{aligned}
$$

$\Gamma(\mathrm{u}, \mathrm{z})=$ the incomplete gamma function and the other symbols have the same meaning as defined previously.

\section{Approximation of the drawdowns in Karoo boreholes}

\section{General}

The discussion above shows that neither the Jacob or Helweg expressions in Eqs. (1) and (2) can fit the observed drawdowns of Karoo boreholes, nor account for the possible non-linear deformation of such an aquifer, or fractal flow. Since it was not obvious how to include these factors into either the Jacob or Helweg equations, a heuristic approach was used to try and adjust these equations for flow in Karoo aquifers.

The recent model of Cloot and Botha (2000) for a horizontal fracture suggested that one can account for the non-linear deformation by splitting the non-linear term in Jacob's equation into two parts - one accounting for the usual effects of turbulence and the other one for the deformation. The model also suggested that the contribution of non-linear deformation will be non-linearly proportional to that of turbulence and time-dependent. Jacob's equation was consequently modified to read

$$
s(t)=B\left(r_{e}, t\right) Q+\left[E Q^{p+e-1}+C^{\prime} Q^{p}\right] \log (t)
$$

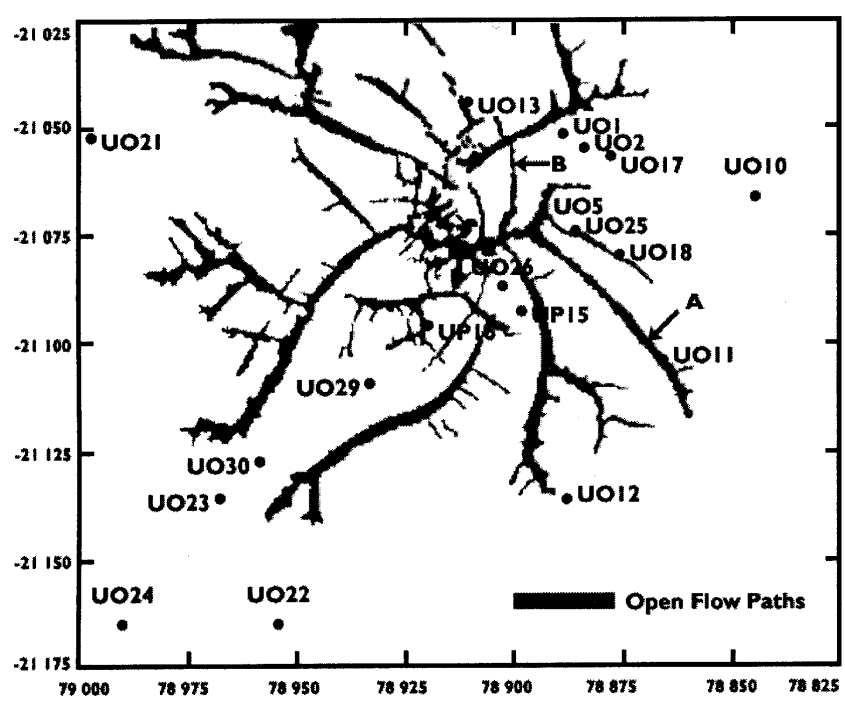

Figure 8

Conceptual model of the horizontal fracture in the sandstone layer that forms the major aquifer at the Campus Test Site

[Adapted from Van der Voort and Van Tonder (2000)]

where the non-linear term has been replaced by the one suggested by Helweg. The exponent $\mathrm{p}+\mathrm{e}-1$ in the term $\mathrm{EQ}^{\mathrm{p}+\mathrm{e}-1} \log (\mathrm{t})$, introduced to account for non-linear deformation of the aquifer, was chosen in such a way that Eq. (6) reduces to Eq. (1) for a fixed time if there is no deformation, that is $\mathrm{e}=1$. The choice was further motivated by the fact that the model of Cloot and Botha indicated that the drawdown would increase if the deformation tends to close the fracture $(\mathrm{e}>1)$. A negative exponent, e, would therefore indicate an opening of the fracture, which is not impossible (Botha et al., 1998).

The analysis of a large number of constant rate and stepdrawdown tests performed on boreholes in the Karoo formations has shown that Eq. (6) cannot account fully for the observed drawdowns. However, further numerical experiments indicated that this can possibly be ascribed to the fractal structure of the fractures in these aquifers (see Fig. 8) and that the equation

$$
s(t)=B\left(r_{e}, t\right) Q+E Q^{p+e-1}(\log t)^{\Gamma(n / 2)}+C^{\prime} Q^{p} \log (t)
$$

with $\mathrm{G}(\mathrm{m})$, the normal Gamma function, and $\mathrm{n}$ Barker's fractal dimension, provide a better approximation for these aquifers.

The approximation in Eq. (7) is very similar to Eq. (1) and, in fact, reduces to it if $\mathrm{e}=1$ and the time is constant. It shares all the advantages of Eq. (1), discussed above, but also the same disadvantages, the most serious of which is that it requires constant time steps in step-drawdown or multi-rate tests. However, the numerical experiments indicated that the same results can also be obtained with the equation

$$
s(t)=A Q+B^{\prime} Q^{e}(\log t)^{\Gamma(n / 2)}+C^{\prime} Q^{p} \log (t)
$$

which arises from Eq. (7) if $\mathrm{B}\left(\mathrm{r}_{\mathrm{e}}, t\right)$ is approximated as

$$
B\left(r_{e}, t\right)=A+Q^{e-2}\left(B^{\prime} Q-E Q^{p}\right)(\log t)^{\Gamma(n / 2)}
$$

Since A is a constant, Eq. (8) can be applied to step-drawdown or multi-rate tests with variable time steps. Unfortunately, there is a price one has to pay for using Eq. (8) (or Eq. (7) for that matter) in that it is no longer possible to use the principle of superposition in 


\begin{tabular}{|c|c|c|c|c|c|c|c|}
\hline \multicolumn{8}{|c|}{$\begin{array}{c}\text { TABLE } 3 \\
\text { Step sizes and discharge rates used during the step-drawdown test performed } \\
\text { on borehole UP16 }\end{array}$} \\
\hline \multicolumn{2}{|c|}{$\begin{array}{c}\text { Step 1 } \\
Q=0.61\left(\ell \cdot \mathrm{s}^{-1}\right)\end{array}$} & \multicolumn{2}{|c|}{$\begin{array}{c}\text { Step 2 } \\
Q=1.18\left(\ell \cdot \mathbf{s}^{-1}\right)\end{array}$} & \multicolumn{2}{|c|}{$\begin{array}{c}\text { Step 3 } \\
Q=2.00\left(\ell \cdot \mathrm{s}^{-1}\right)\end{array}$} & \multicolumn{2}{|c|}{$\begin{array}{c}\text { Step } 4 \\
Q=3.50\left(l \cdot \mathrm{s}^{-1}\right)\end{array}$} \\
\hline $\begin{array}{l}\text { Time } \\
\text { (min) }\end{array}$ & $\begin{array}{c}\mathrm{s} \\
(\mathrm{m})\end{array}$ & $\begin{array}{l}\text { Time } \\
(\min )\end{array}$ & $\begin{array}{c}\mathbf{s} \\
(\mathrm{m})\end{array}$ & $\begin{array}{l}\text { Time } \\
(\min )\end{array}$ & $\begin{array}{c}\mathbf{s} \\
(\mathrm{m})\end{array}$ & $\begin{array}{l}\text { Time } \\
(\min )\end{array}$ & $\begin{array}{c}\mathbf{s} \\
(\mathrm{m})\end{array}$ \\
\hline 0 & 0.000 & 22 & 0.730 & 47 & 1.660 & 65 & 3.150 \\
\hline 2 & 0.170 & 23 & 0.780 & 48 & 1.740 & 66 & 3.300 \\
\hline 3 & 0.190 & 24 & 0.830 & 49 & 1.810 & 67 & 3.440 \\
\hline 4 & 0.230 & 25 & 0.870 & 50 & 1.875 & 68 & 3.560 \\
\hline 5 & 0.265 & 26 & 0.910 & 51 & 1.940 & 69 & 3.670 \\
\hline 6 & 0.295 & 27 & 0.960 & 52 & 1.995 & 70 & 3.770 \\
\hline 7 & 0.320 & 28 & 0.990 & 53 & 2.050 & 71 & 3.870 \\
\hline 8 & 0.350 & 29 & 1.010 & 54 & 2.100 & 72 & 3.970 \\
\hline 9 & 0.375 & 30 & 1.045 & 55 & 2.150 & 73 & 4.085 \\
\hline 11 & 0.425 & 31 & 1.070 & 56 & 2.200 & 74 & 4.175 \\
\hline 12 & 0.450 & 32 & 1.100 & 57 & 2.255 & 75 & 4.260 \\
\hline 13 & 0.460 & 33 & 1.135 & 58 & 2.290 & 76 & 4.350 \\
\hline 14 & 0.480 & 34 & 1.160 & 59 & 2.325 & 77 & 4.430 \\
\hline 15 & 0.500 & 35 & 1.180 & 60 & 2.370 & 78 & 4.510 \\
\hline 16 & 0.520 & 36 & 1.200 & 61 & 2.405 & 79 & 4.585 \\
\hline 17 & 0.535 & 37 & 1.230 & 62 & 2.450 & 80 & 4.660 \\
\hline 18 & 0.550 & 38 & 1.250 & 63 & 2.490 & 81 & 4.730 \\
\hline 19 & 0.565 & 39 & 1.275 & 64 & 2.520 & 82 & 4.800 \\
\hline 20 & 0.585 & 40 & 1.290 & & & 83 & 4.870 \\
\hline 21 & 0.600 & 41 & 1.315 & & & 84 & 4.940 \\
\hline & & 42 & 1.335 & & & 85 & 5.000 \\
\hline & & 43 & 1.355 & & & 86 & 5.060 \\
\hline & & 44 & 1.370 & & & 87 & 5.120 \\
\hline & & 45 & 1.390 & & & 88 & 5.180 \\
\hline & & 46 & 1.410 & & & 89 & 5.240 \\
\hline & & & & & & 90 & 5.290 \\
\hline & & & & & & 95 & 5.540 \\
\hline & & & & & & 97 & 5.640 \\
\hline & & & & & & 100 & 5.760 \\
\hline & & & & & & 105 & 5.960 \\
\hline & & & & & & 113 & 6.220 \\
\hline & & & & & & 114 & 6.270 \\
\hline & & & & & & 115 & 6.290 \\
\hline & & & & & & 116 & 6.310 \\
\hline & & & & & & 117 & 6.340 \\
\hline & & & & & & 118 & 6.370 \\
\hline & & & & & & 119 & 6.400 \\
\hline & & & & & & 120 & 6.430 \\
\hline
\end{tabular}

TABLE 4
\begin{tabular}{|c|c|c|c|c|r|}
\hline $\begin{array}{c}\text { Values of the coefficients that describe the fit } \\
\text { of Eq. (8) to the observed drawdowns of UP } 16 \\
\text { in Fig. 9 }\end{array}$ \\
\hline A & B & C & p & n & e \\
\hline $7.5 \cdot 10^{-4}$ & $4.36 \cdot 10^{-3}$ & $2.88 \cdot 10^{-6}$ & 2.0 & 1.48 & 1.12 \\
\hline
\end{tabular}

the analyses of step-drawdown or multi-rate tests. The reason for this is that both the B' and C' terms contain fractional exponents of $\mathrm{Q}$, and cannot be linearised by dividing the equation with $\mathrm{Q}$. Moreover, the objective function that arises if one attempts to fit Eq. (8) with a non-linear least squares method to the observed drawdowns is non-convex (this also applies to Helweg's equation). An interactive method, called the non-linear FC-method was developed and implemented in the FC-program, which is available as an Excel workbook on the website of the Institute for Groundwater Studies at the University of the Free State (www.uovs.ac.za/ faculties/igs). The workbook also allows the user to use a nonlinear least square fit if required, but this is not recommended for 


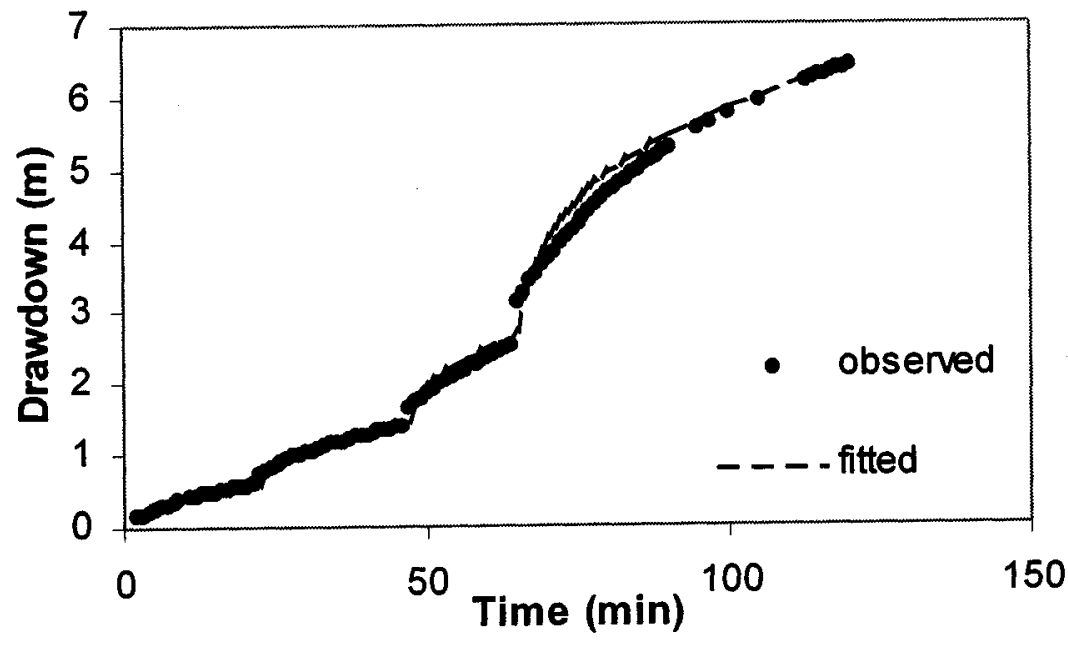

Figure 9

Graph of Eq. (8) when fitted to the drawdowns observed during the step-drawdown test performed on Borehole UP16

someone who does not have experience with non-linear least squares approximations.

\section{A case study}

It is not possible to describe all the step-drawdown tests that have been used in developing Eq. (8). The present discussion will be concluded with just one example, the step-drawdown test performed on Borehole UP16 on the Campus Test Site (see Fig. 8 for its position). This borehole intersects the bedding parallel fracture on the site at a depth of $21 \mathrm{~m}$ below the surface, while its rest water level at the time of the test was $13.2 \mathrm{~m}$ below the surface. TABLE 3 lists the discharge rates and drawdowns observed during the four steps used in the test. The observed drawdowns are also compared graphically with the interactive fit to Equation (8) in Fig. 9.

The coefficients determined from the fit of $s(t)$ (expressed in $\mathrm{m})$, Q (expressed in $\mathrm{m}^{3} \cdot \mathrm{d}^{-1}$ ) and $\mathrm{t}$ (expressed in d) to Eq. (8), are listed in Table 4 . These values were used to estimate the drawdown in the borehole for a period of 2 years, such that the drawdown would not reach the position of the bedding parallel fracture. In other words, $\mathrm{s}$ should not exceed $7.8 \mathrm{~m}$ (=21 m to $13.2 \mathrm{~m})$. This yielded a discharge rate of $0.5 \ell \cdot \mathrm{s}^{-1}$, which agrees with the value $0.48 \ell \cdot \mathrm{s}^{-1}$ obtained by Van Tonder et al. (2001) with the normal FC-method.

\section{Conclusions}

Drawdown tests are frequently the only tool available with which to assign sustainable yields for boreholes. This applies in particular to boreholes in the Karoo formations of South Africa. The drawdown curves in these boreholes, unfortunately, regularly display a nonlinear behaviour that cannot be attributed to turbulent effects in the borehole alone. Two new generalised equations (Eqs. 7 and 8) were derived in this paper to analyse step-drawdown tests data in these aquifers.

There is no doubt that Eq. (7) applied to a series of at least six (preferably more) multi-rate tests will yield the most reliable results. However, these tests can be very time-consuming and expensive. In such cases the user may find the approximation in Eq. (8), which allows the use of the more economical step-drawdown tests with variable time steps more suitable. However, the yield estimated from this analysis should preferably be monitored for some time after the borehole is used for production purposes.

Non-linearities in drawdown curves should always be treated with caution, especially when used to assign sustainable yields for boreholes. This applies in particular to the extrapolation of the results into domains not covered during the test. The recommendation by Helweg (1994) that the tests be designed to reach the maximum possible drawdown and discharge rate cannot be overemphasised. In the case of boreholes in Karoo aquifers, the maximum drawdown is when the water level reaches the main water-bearing fracture. This depth should never be exceeded, not even during the drawdown test, if one does not want to damage the borehole.

\section{Acknowledgement}

The authors would like to thank the Water Research Commission for its financial support of the project. A special word of thanks also to $\mathrm{Mr}$ Kevin Pietersen of the Commission for his words of encouragement and Dr. Erik Tordiffe of NAMWATER, Namibia, for permission to use the Khorixas pump test data.

\section{References}

BARKER JA (1988) A generalized radial flow model for hydraulic tests in fractured rock. Water Resour. Res. 24 (10) 1796-1802.

BEAR J (1972) Dynamics of Fluids in Porous Media. American Elsevier Environmental Science Series. American Elsevier Publishing Company, Inc., New York.

BOTHA JF (1996) Principles of Groundwater Motion. Unpublished Lecture Notes. Inst. for Groundwater Studies, Univ. of the Orange Free State, PO Box 339, Bloemfontein 9300.

BOTHA JF, VERWEY JP, VAN DER VOORT I, VIVIER JJP, COLLISTON WP and LOOCK JC (1998) Karoo Aquifers. Their Geology, Geometry and Physical Behaviour. WRC Report No 487/1/98.

CAKMAK AS and BOTHA JF (1995) Applied Mathematics for Engineers. Computational Mechanics Publications, Southampton.

CLOOT AHJ and BOTHA JF (2000) Modelling Groundwater Flow in an Elastic, Confined Aquifer. Draft Report to the Water Research Commission. Inst. for Groundwater Studies, Univ. of the Free State, PO Box 339, Bloemfontein 9300.

GRINGARTEN AC and RAMEY HJ (1974) Unsteady-state pressure distributions created by a well with a single horizontal fracture, partial penetration, or restricted entry. Soc.of Pet. Eng. J. 14 (5) 413-426. 
HELWEG OJ (1994) A general solution to the step-drawdown test. Ground Water 32 (3).

JACOB CE (1947) Drawdown test to determine effective radius of artesian well. Am. Soc. of Civ. Eng. Trans. 112 (Paper 2321) 1047-1064.

KRUSEMAN GP and DE RIDDER NA (1991)Analysis and Evaluation of Pumping Test Data ( $2^{\text {nd }}$ edn.) Publication 47. International Inst. for Land Reclamation and Improvement, PO Box 45, 6700 Wageningen, The Netherlands.

MATTHEWS CS and RUSSELL DG (1967) Pressure Buildup and Flow Tests in Wells. Storm Printing Corporation, Dallas, Texas.
VAN DER VOORT I and VAN TONDER GJ (2000) Analysing the geometry of South African fractured rock aquifers. In: Sililo O (ed.) Proc. of the XXXth IAH Congr. on Groundwater: Past Achievements and Future Challenges, Cape Town, South Africa. A.A. Balkema, Rotterdam.

VAN TONDER GJ, BOTHA JF, CHIANG W-H, KUNSTMANN H and XU Y (2001) Estimation of the sustainable yields of boreholes in fractured rock formations. J. of Hydrol. 241 70-90. 